\title{
The Effectiveness Of Incidental Teaching Of Grammar To Iranian Students
}

\author{
Z. Ghabanchi, Sabzevar Teacher Training University, Iran
}

\begin{abstract}
This article reports the results of a study and a pilot study. The 'study' considers the effectiveness of incidental teaching of grammar in a learning class of English As A Second Language by Persian speaking students. The 'pilot study' examines the students' attitudes toward the incidental learning of grammar from the perspective of field dependent/independent ${ }^{l}$. The subjects of this study are two groups of EFL learners, a total of 30 students studying at Sabzevar Payam Noor University, Iran. English proficiency was measured by the TOEFL and an oral test of communicative competence. Grammar is presented in two series of lessons. The first, a series of ten grammar lessons, provides an intensive review of grammatical points for beginning ESL students. These lessons assume a low vocabulary level, include a simple grammatical generalization, and provide extensive practice of specific grammar points using a wide variety of exercises. A built-in review is provided for items that are missed in each exercise. The second series, six advanced grammar lessons, provides extensive reinforcement and practice of a wide range of advanced grammar points. Each lesson consists of at least four mechanical exercises, including substitution, transformation, question/answer, and fill-in-the-blank drills. The focus in this study is on learning grammar, in general, and passive voice, in particular. A pre-test is administered to be certain. This test consists of 60 multiplechoice questions. The subjects fortunately are almost at the same level; the averages are very close. The subjects were divided into two groups: control and experimental. Then the easy texts, which include the grammatical points, are taught incidentally to the experimental group, whereas explicitly to the control group. A test is carried out for the groups. Then in the following term, the same groups are taught the advance materials followed by a test. The results indicate that the use of an incidental method of teaching does not show a significant priority over the explicit one. In reality, the control group does better, especially with the advanced materials. Concerning the pilot study, a questionnaire is distributed among the subjects to identify the field dependent/independent ones. The aim of this pilot study is to identify what kinds of students are more interested in incidental learning of grammar. Five students are selected from each group. The analysis of the data concerning their reception of the method of teaching and the outcome of the groups is carried out. The study does not show a significant difference between field dependent/independent students concerning incidental learning.
\end{abstract}

Keywords: incidental learning, learning, grammar, methods of teaching, field dependent, field independent

\section{INTRODUCTION}

( $\mathrm{n}$ language teaching in general, and that of grammar in particular, there exist two popular methods, both of which are utilized across the globe in language classes. The deductive approach to language learning is a method in which the grammatical rules are explicitly presented to students followed by practice applying the rule. As a reaction to this way of teaching grammar, other alternatives are proposed, such as inductive learning, discovery learning, noticing and conscious-raising (Fortune, 1992; James, 2001). The results of applying these approaches to teaching grammar have not been consistent in different situations, nor for individuals (Fortune, 1992; James, 2001). Consequently, the concept of incidental learning comes into vogue. It is crucial for learners to acquire or learn some amount of data without intention. The importance of the present study lies here. Through

${ }^{1}$ Field independence/dependence. Field independence/dependence (FI/D), a cognitive variable, is defined as "the extent to which a person perceives part of a field as discrete from the surrounding field as a whole, rather than embedded, or ... the extent to which a person perceives analytically" (Witkin, Moore, Goodenough, \& Cox, 1977, p. 7). A field independent (Fl) person tends to approach problem-solving analytically, while a field dependent (FD) person tends to approach problem-solving in a more global way. 
the results obtained, one can hope to depict whether it is more appropriate to learn grammar incidentally or explicitly by concentrating on the rules.

According to Lankard (1995), incidental learning, to a noticeable extent, increases specific knowledge, skills and understanding. Incidental learning includes learning from mistakes, learning by doing, and learning through a series of interpersonal experiments. On the other hand, intentional learning means learning as a result of purposeful activity; i.e. when a person is going to learn something.

The common idea of incidental teaching is that they do not start with overt introduction of a rule; but as one can gather from the titles, the learner is encouraged to discover the rules from the texts and the milieu of instruction.

In this study, an endeavor is made to investigate the role of incidental learning of grammar in reading tasks as compared to the effect of explicit teaching of grammar.

\subsection{Statement of the Problem}

The question of the study is, "In which case is grammar learned effectively, when it is taught incidentally or when it is presented explicitly?"

\section{REVIEW OF THE RELATED LITERATURE}

Many teachers have long known that students often don't learn the grammar they are taught; they only internalize those grammar features that they are ready to learn and they learn each feature very gradually, passing through a series of transitional stages.

"Learning is a relatively permanent change in a behavioral tendency and is the result of reinforced practice" (Kimble and Garmezy, 1965, cited in Brown, 1994, p. 87).

Concerning the role of incidental learning, Schmidt (1990) maintains that incidental learning is certainly possible when the task demands focusing attention on relevant features of the input. In addition, Ellis (1994, p. 139) stresses that "many formal language lessons are not directed at properties but rather at enabling the learners to use features they have partly acquired with greater accuracy".

Schmidt (1990) argues that consciousness and intentionality must be separated, as we often become aware of things we do not intend to notice; however, he does not show significant evidence for his claim. In addition, Schmidt makes a strong claim for the possibility of incidental learning taking place while the focus of learning is on the other relevant and important points.

While focusing on the form has been shown to produce short-term gains in the accurate production or recognition of certain linguistic structures, the long-term effects of such instruction have not been confirmed, and evidence that such input is necessary is not conclusive (White, 1990; Lightbown \& Spada, 1991; Carrell \& Swain, 1993; Mackey et al., 2004; and Sheen, 2003). Ron Sheen (2003, p. 225) goes so far as to call focusing on the form a "myth in the making".

In support of the incidental teaching view, Long (2000, p. 95) cites, "Given adequate opportunities, older children, adolescents, and adults can and do learn much of the grammar of a second language incidentally while focusing on meaning or communication." This position is also backed by Lightbown (2000, p. 432) who maintains that "classroom research has provided additional support for the conclusion that some features are acquired incidentally without intentional effort or pedagogical guidance". However, he does not show which feature can be acquired incidentally. 


\section{1. Explicit and Implicit Teaching}

Explicit knowledge is knowledge about grammar; i.e. understanding the rules and implicit knowledge is knowledge of grammar; i.e. knowing the rules in an intuitive way that enables them to be accessed quickly and easily for purposes of communication. It is this kind of knowledge that underlies the learner's built-in syllabus and which is acquired gradually. We can avoid the difficulties of trying to match the teaching syllabus to the learner's syllabus if we make explicit, rather than implicit, knowledge the target of instruction.

Of course, such a solution only makes sense if it can be shown that learning explicit knowledge is useful. Current theories of second language learning suggest that explicit knowledge is important in a number of respects. First, it teaches learners to be more grammatically accurate by monitoring what they say or write. They can 'edit' out some of the errors they make because they have not yet acquired the necessary implicit knowledge. Second, explicit knowledge can teach learners how to acquire implicit knowledge. "If learners understand how a grammatical feature works, they will be more likely to notice it when they are listening or reading. Current theories claim that noticing is essential for the development of implicit knowledge" (Ellis \& Gaies, 1998).

Ellis and Gaies (1998) have issued some materials designed to teach grammar through awareness-raising (Ellis and Gaies 1998). Each unit is based on a grammatical problem that we know learners of English As A Second Language commonly experience (e.g. the use of the present progressive tense with stative verbs, such as in "I am weighing 60 kilos."). The learners begin by listening to text that contains examples of correct usage. They first process this for meaning; then they listen again while focusing their attention on the targeted grammatical feature (i.e. they are helped to notice it). Next, they use the data to try to arrive at an explicit understanding of the rule (e.g. the kinds of verbs that are not used in the present progressive tense). This provides a basis for an error-identification task where they can check to see if they understand the rule clearly. Finally, there is an opportunity for the learners to try to use the correct grammatical structure in their own sentences.

\section{$2.2 \quad$ Research Hypothesis}

H0: Teaching grammar incidentally can help the student to learn better.

If the data show the superiority of incidental teaching, this hypothesis is strengthened.

\subsection{Research Question}

The question of the present research is as follow:

- Can incidental teaching of grammar be more effective than the explicit method?

\section{METHOD}

\subsection{Design of the Study}

This study fairly meets the conditions of true experimental studies (i.e. using a control group, random selection, random assignment of students to control, and experimental groups, etc.).

\subsection{The Subjects of Study}

The subjects of this study are two groups of EFL learners (a total of 30 students; 22 female and 8 male), all studying at Sabzevar Payam Noor University, Iran. The age group of the subjects is 19 to 25 .

\subsection{Procedure}

Grammar is presented in two series of reading lessons. The first is a series of ten grammar lessons, which provides an intensive review of grammatical points for beginning ESL students. These lessons assume a low 
vocabulary level, include a simple grammatical generalization, and provide extensive practice of specific grammar points using a wide variety of exercises. A built-in review is provided for items that are missed in each exercise. The second series consists of six advanced grammar lessons and provides extensive reinforcement and practice of a wide range of advanced grammar points. Each lesson consists of at least four mechanical exercises, including substitution, transformation, question/answer, and fill-in-the-blank drills. For the control group, grammar was taught explicitly through examples and elaboration on the exercise, while for the experimental group, teaching was carried out incidentally via the use of reading texts that have the grammatical points.

The focus in this study is on learning grammar, in general, and passive voice, in particular. An attempt is made to be sure that the subjects had no exposure to passive voice instruction. To achieve this, a pre-test is administered to be certain. The test consists of 60 multiple-choice questions. The subjects were divided into two groups: control and experimental. First, the easy texts, which include the grammatical points, are taught incidentally to the experimental group, whereas explicitly to the control group. A test is then carried out for the groups. Then in the following term, the same groups are taught the advanced materials and a test is carried out. The results indicate that the use of the incidental method of teaching does not show a significant priority over the explicit one. In reality, the control group does better, especially with the advanced materials.

Concerning the pilot study, a questionnaire is distributed among the subjects to identify the field dependent/independent ${ }^{2}$ ones. The aim of this pilot study is to identify what kinds of students are more interested in incidental learning of grammar. Five students are selected from each group and an analysis of the data concerning their reception of method of teaching and the outcome of the groups is carried out. The study does not show a significant difference between field dependent/independent students concerning incidental learning.

\section{RESULTS}

The data were analyzed using SPSS. A series of analyses was done to address the first question, "What kind of student likes to respond better to incidental learning?" Pearson product-moment correlations were calculated; then a T-Test analysis was performed.

It is essential to analyze the differences between the means to decide which approach of teaching grammar has been more effective (implicit teaching or explicit). If students' performance in the experimental group is better than the control group, then the hypothesis is turned down.

A paired sample T-test was conducted to evaluate the impact of intervention (treatment/implicit teaching of grammar) in the experimental group of students' scores on a grammatical structure test. There was not a statistically significant increase in the scores.

Table 1: T-Test

\begin{tabular}{|c|c|c|c|c|}
\hline Code & N & Mean & Std. Deviation & Std. Error Mean \\
\hline Difficult Control G & 15 & 66.13333 & 13.6112 & 3.51441 \\
\hline Difficult Experimental G & 15 & 60.30 & 15.53 & 4.0073 \\
\hline
\end{tabular}

Table 2: Independent Sample Test

\begin{tabular}{|l|c|c|c|c|c|c|c|c|c|}
\hline & $\begin{array}{l}\text { Levene's Test } \\
\text { for Equality } \\
\text { Variance }\end{array}$ & \multicolumn{9}{|c|}{$\begin{array}{c}\text { T-Test for Equality of Means } \\
\text { 95\% Confidence } \\
\text { Internal of the Difference }\end{array}$} \\
\hline $\begin{array}{l}\text { Difficult Equal } \\
\text { Variances Assumed }\end{array}$ & $\mathrm{F}$ & Sig. & $\mathrm{t}$ & $\mathrm{df}$ & $\begin{array}{c}\text { Sig.2- } \\
\text { Tailed }\end{array}$ & $\begin{array}{c}\text { Mean } \\
\text { Difference }\end{array}$ & Std. Error Difference & Lower Upper \\
\hline & 0.15 & .905 & 1.113 & 28 & .275 & 5.93333 & 5.33012 & -4.9849 & 16.851 \\
\hline
\end{tabular}

${ }^{2}$ Field independence/dependence. Field independence/dependence (FI/D), a cognitive variable, is defined as "the extent to which a person perceives part of a field as discrete from the surrounding field as a whole, rather than embedded, or ... the extent to which a person perceives analytically" (Witkin, Moore, Goodenough, \& Cox, 1977, p. 7). A field independent (Fl) person tends to approach problem-solving analytically, while a field dependent (FD) person tends to approach problem-solving in a more global way. 
Table 3: T-Test

Group Statistics

\begin{tabular}{|c|c|c|c|c|}
\hline Code & N & Mean & Std. Deviation & Std. Error Mean \\
\hline Easy Control G & 15 & 73.6667 & 13.5997 & 3.5114 \\
\hline Easy Experimental G & 15 & 70.000 & 16.1378 & 4.16676 \\
\hline
\end{tabular}

Table 4: Independent Sample Test

\begin{tabular}{|l|c|c|c|c|c|c|c|c|}
\hline & \multicolumn{2}{|c|}{$\begin{array}{c}\text { Levene's Test } \\
\text { for Equality } \\
\text { Variance }\end{array}$} & \multicolumn{3}{|c|}{ T-Test for Equality of Means } & $\begin{array}{c}\text { 95\% Confidence } \\
\text { Internal of the Difference }\end{array}$ \\
\hline $\begin{array}{l}\text { Easy Equal } \\
\text { Variances Assumed }\end{array}$ & $\mathrm{F}$ & Sig. & $\mathrm{t}$ & $\mathrm{df}$ & $\begin{array}{c}\text { Sig.2- } \\
\text { Tailed }\end{array}$ & $\begin{array}{c}\text { Mean } \\
\text { Difference }\end{array}$ & Std. Error Difference & Lower Upper \\
\hline & .331 & .570 & .673 & 28 & .507 & 3.66667 & 5.44904 & -7.4951914 .8285 \\
\hline
\end{tabular}

Table 5: Correlations

\begin{tabular}{|l|c|c|}
\hline & Difficult 1 & Difficult 2 \\
\hline Difficult1 Pearson Correlation Sig. 2-Tailed & 1 & $.537^{*}$ \\
N & & .039 \\
& 15 & 15 \\
\hline Difficult1 Pearson Correlation Sig. 2-Tailed & $.537^{*}$ & 1 \\
N & .039 & 15 \\
\hline
\end{tabular}

Table 6: Correlations

\begin{tabular}{|l|c|c|}
\hline & Easy 1 & Easy 2 \\
\hline Easy1 Pearson Correlation Sig. 2-Tailed & 1 & .410 \\
N & & .129 \\
& 15 & 15 \\
\hline Difficult1 Pearson Correlation Sig. 2-Tailed & .410 & 1 \\
N & .129 & 15 \\
\hline
\end{tabular}

The above tables show that accordingly, the difference between both groups is not so significant; however, the students of the explicit teaching group had a rather better outcome compared to the other group.

As the results clarify, there is no significance in the scores on the pre-test and post-test of the experimental group that had been learning grammar incidentally through reading texts, which shows that in the case of taking a multiply-choice test, the students did not make any considerable improvement in scores. In this case and according to the result of this study, we can come to the conclusion that incidental learning of grammar is not very productive in all situations. However, on the other hand, we can observe the significance in the scores obtained by the control group that was taught grammar explicitly on their post-test in comparison to their pre-test. In such an analysis, we can argue that teaching grammar explicitly is useful.

\section{CONCLUSION}

The research reported here casts a new light on the question of incidental teaching effectiveness in the context of L2 acquisition. Incidental teaching cannot be evaluated without looking at the other student variables some of which were not assessed in this study - that are important in L2 acquisition. It would have appeared that the use of incidental teaching predicted low ESL proficiency scores if other variables had not been considered. Relevant student variables must also be taken into account in a control treatment design assessing use of incidental teaching versus no use of incidental teaching. 
As the results clarify, there is no significance in the scores on the pre-test and post-test of the experimental group that had been learning grammar incidentally through reading texts. On the other hand, we can observe the significance in the scores obtained by the control group that was taught grammar explicitly on their post-test in comparison to their pre-test. The study answers the question at hand. There is no significant difference between the groups with the easy lessons and tasks, but a slight difference with the harder material. Generally speaking, the explicit way of teaching grammar works slightly better than incidental learning of grammar, especially at the advanced level.

The purpose of such an approach is to provide students with remedial tasks that address not only the content area in which they are having problems, but also the method of teaching that they do not naturally employ. These possibilities for individualized instruction might be greatly enhanced through the use of interactive, on-line activities for students with special problems. Although, in some sense, this application of research is premature, it points toward a possibly fruitful direction for incidental reading to explore.

It has been realized that in the area of intellectual problem-solving, a highly FI person is able to detect patterns and sub-patterns, while a field dependent (FD) person tends to get lost in the totality of the stimuli. Consequently, a field independent (FI) person is at an advantage in problem-solving situations in which isolating and manipulating a critical element are important.

A FD person, on the other hand, is more capable of perceiving the total picture in a situation. A FI person may have good analytical language skills, such as those needed in many classroom environments, while the FD person would logically be better at acquiring a second language through interaction with native speakers in social situations. However, the result of the pilot study did not significantly support any specific claim.

It might be possible to infer that the students may prefer to use their natural abilities to structure information rather than to be presented with lessons that define the course of their learning - a suggestion consistent with the FI individual defined by Witkin et al. (1977). However, it is necessary to ask not only what kind of instruction FI students might like, but also what kind of lessons they might benefit from. There is some evidence indicating that learners are more successful when the method employed in a particular learning activity matches their cognitive style.

It is necessary to assess the characteristics of students and analyze the approach taken in a particular lesson or series. Through this observation of students and approaches, progress can be made toward successful matching of students and lessons. This is not a new idea; instead, these results emphasize the importance of the cognitive approach in educational research.

We have not yet considered the surface of what incidental teaching can provide in terms of individual instruction for language learners. Researchers and educators must continue to describe the strategies used by good language learners and to assess cognitive/affective characteristics that are important in L2 acquisition.

In general, it appears that the use of incidental teaching can be a positive factor. However, teacher trainers should exercise a certain degree of caution when advising or implementing incidental teaching.

\section{AUTHOR INFORMATION}

Zargham Ghabanchi was born in 1961. He received his BA in English language and literature from Mashed University in Iran. Then he received his MA in TEFL from Tehran Tarbiayyet Moderres University, Iran. He started his Ph.D. at the University of Liverpool, the UK in 1993 and Ph.D. was conferred to him in 1998 in Applied Linguistics. Now he has a chair at Sabzevar Teacher Training University and he is the vice chancellor of Sabzevar Payam Noor University. He has published several books and articles. 


\section{REFERENCES}

1. Brown, H. D. (1994). Principles of language learning and teaching. Englewood Cliffs NJ: Prentice Hall.

2. Ellis, R. (1994). Can syntax be taught ? A study of the effects of formal instruction on the accquisition of Wh-questions by children. Applied Linguistics, 5, 138-155.

3. Ellis, R. and Gaies, S. (1998). Impact Grammar. Hong Kong: Longman. (online). available in April, 2008 on: http://www.impactseries.com/grammar/making.html

4. Ellis, R. (2001). Second language acquisition: The role of consciousness. New Zealand: University of Auckland.

5. Fortune, A. (1992). Self-study grammar practice: Learners' views and preferences. ELT Journal , 46(6), 160-171.

6. Hatch, E. \& Lazaraton, A. (1991). The research manual.New York: Newbury House Publishers.

7. James, M. R. (2001). Conscious-raising versus deductive approaches to language Instruction: A Study of Learner Preferences. University of Birmingham.

8. Krashen, S. (1981). Second language acquisition and second language learning. Oxford: Pergamon.

9. Lankard, B. A. (1995). New ways of learning in the workplace. ERIC Digest 161. Columbus (OH): ERIC Clearinghouse.

10. Lightbown, P. \& Spada, N. (1991). Focus-on-form and corrective feedback in communicative language teaching. Studies in Second Language Acquisition,12, 429- 444.

11. Lightbown, P. (2000). Anniversary article: Classroom SLA research and second language teaching. Applied Linguistics, 21 , 431- 462.

12. Long, M. (2000). Focus on form in task-based language teaching in Language policy and pedagogy http://www.learning.org/OldArticles/syntax\%20archive\%20and\%20reading.pdf

13. Mackey, A.. Polio, C. \& McDonough, K. (2004). The relationship between experience, education, and teacher's use of incidental focus on form techniques. Language Teaching Research, 8(3), 55- 81.

14. Schmidt, R. (1990). The role of consciousness in second language learning. Applied Linguistics, 11, 129158.

15. Schmidt, R. (1993). Deconstruction of consciousness in search of useful definition for applied linguistics. In J. Hulstiyn and R, Schmidt (Eds.). Consciousness in Second Language Learning. AILA Review 11 (pp. 85-97).

16. Sheen, R. (2003). Focus on form : a myth in the making ? ELT journal, 57(3), 225-233(online). Available: http:// www.Scientificjournals.org/articles/1124.html.

17. White, L. (1990). Second language acquisition and universal grammar. Studies in Second Language Acquisition, 12, 121-133. 


\section{NOTES}

